\title{
PRODUCCIÓN LIMPIA Y BIORREMEDIACIÓN PARA DISMINUCIÓN DE LA CONTAMINACIÓN POR CROMO EN LA INDUSTRIA DE CURTIEMBRES
}

\author{
Cleaner production and bioremediation for reduction of pollution in the \\ industry of chrome tannery \\ NEYLA BENITEZ-CAMPO ${ }^{1}$ \\ ${ }^{1}$ Universidad del Valle, Cali, Colombia
}

E-mail: neyla.benitez@correounivalle.edu.co

Recibido: 15 de Junio de 2010

Aceptado: 9 de Febrero de 2011

\section{Resumen}

En este documento se presentan algunos acontecimientos que explican los efectos de la relación antropogénica con los recursos naturales como consecuencia de la industrialización. Posteriormente se describe el uso y potencial contaminante del cromo, metal ampliamente utilizado a nivel industrial y se plantean los beneficios de emplear métodos biotecnológicos para la recuperación del cromo en el sector de las curtiembres, con un enfoque preventivo, basándose en los programas de producción más limpia, con el que se propone implementar un manejo integral para disminución de la contaminación por cromo.

Palabras claves: Biorremediación, Contaminación industrial, Cromo, Curtiembres, Producción más limpia.

\section{Abstract.}

This paper presents some events that explain the effects of anthropogenic relationship with natural resources as a result of industrialization. Then we describe the use and potential pollution of chromium metal widely used at industrial and consider the benefits of using biotechnological methods for the recovery of chromium in the tanning industry, with a preventive approach, based on cleaner production programs, which management intends to achieve comprehensive approach pollution reduction by chromium.

Keywords: Biorremediation, Industrial contamination, Chromium, Tannery, Cleaner production. 


\section{Producción limpia y biorremediación en Curtiembres}

\section{INTRODUCCIÓN}

La contaminación es uno de los fenómenos de degradación del medio ambiente que se ha convertido en una situación común en países de todas las latitudes, con diversos niveles de desarrollo y culturas diferentes. Uno de los factores que ha propiciado el aumento de la contaminación es el sector industrial que utiliza sustancias tóxicas en los procesos de manufactura de sus productos, como en el caso de los metales pesados, que por su naturaleza, suelen acumularse y/o transformarse en el ambiente, constituyéndose en altamente peligrosos por el riesgo de toxicidad hacia los organismos vivos. Entre los metales pesados vertidos al ambiente como producto de la actividad industrial, está el cromo, que en su estado de $\mathrm{Cr}^{+3}$ constituye un microelemento esencial, pero en presencia de materia orgánica y condiciones ligeramente ácidas suele transformarse a $\mathrm{Cr}^{+6}$, considerado causante de enfermedades alérgicas, respiratorias, así como un potente agente cancerígeno, y mutagénico en humanos. $\mathrm{El} \mathrm{Cr}^{+3}$ es utilizado en industrias de pinturas, en metalurgia, en la industria refractaria, en electrogalvanizados, en curtiembres de cuero, entre otras.

La industria de curtiembres contribuye especialmente a la contaminación por cromo, al consumir aproximadamente el $32 \%$ del cromo total mundial, que al ser vertido al ambiente suele acumularse en los sedimentos y o transformase en el ambiente. En los últimos años se han propuesto métodos químicos para remover el cromo del lodo de curtiembres, infortunadamente estas técnicas tienen dificultades por los altos costos y dificultades operacionales. Con el propósito de disminuir la contaminación por cromo se plantea aplicar métodos biotecnológicos, con microorganismos capaces de sedimentar el metal pesado por mecanismos de biolixiviación que han mostrado ser más económicos que los métodos químicos, disminuyendo en un $80 \%$ los costos de funcionamiento. Se propone aplicar métodos de biorremediación para precipitación y recuperación del metal pesado en el sector de las curtiembres, con un enfoque preventivo con el que se busca incrementar la eficiencia en el manejo de los recursos naturales, humanos y financieros.

\section{CONTAMINACIÓN INDUSTRIAL}

El problema de la contaminación está ligado a factores económicos, sociales y políticos; que han conducido a un deterioro de los recursos naturales por el propósito de acumular capital, la satisfacción de necesidades de una población que crece aceleradamente y que suele concentrarse en grandes centros urbanos, aumentando los problemas de contaminación. Se entiende por contaminación industrial la emisión directa o indirecta de sustancias nocivas, tóxicas o peligrosas, hacia el medio natural que afectan la salud del ser humano, la calidad de vida o el funcionamiento natural de los ecosistemas (Henry \& Heinke 2006).

Puede afirmarse que los principales sucesos de degradación ambiental tienen sus inicios en el proceso de industrialización a mediados del siglo XVIII, con la revolución industrial, que surge en Londres y que precisamente fue la primera ciudad en la que se instauró el capitalismo (Sarlingo 1998); sistema de producción que conlleva a la aceleración del flujo entrópico de energía y materiales, producción masiva de bienes y servicios y consumo inmoderado (González de Molina 1993). Este sistema llevó a la progresiva mecanización de la producción y a la paulatina sustitución de energía humana por cantidades crecientes de materiales y combustibles fósiles. Por tanto, el proceso de producción de mercancías en la actualidad es el resultado del elevado consumo de energía y materiales del sistema industrial dentro de procesos productivos cada vez más complejos y sofisticados (Gligo 2001).

La industrialización trajo consigo una revolución en la cantidad, intensidad y variedad de contaminantes vertidos al ambiente, que dieron origen a zonas de contaminación concentrada y de degradación medioambiental: paisajes destruidos por emanación de gases tóxicos, enormes escoriaciones de materiales de desecho, corrientes de agua llenas de residuos industriales tóxicos y destrucción de la vegetación en todas las zonas circundantes (Sarlingo 1998, González de Molina 1993). Después de la II Guerra Mundial los países industrializados experimentaron un florecimiento económico estimulado por el crecimiento de la población, avances tecnológicos y el rápido incremento del consumo de energía fósil. Los nuevos productos químicos, entre ellos los plaguicidas, detergentes, plásticos, metales pesados, explosivos, principalmente, causaron y continúan causando enormes problemas ambientales (Henry \& Heinke 2006).

La industrialización en los países en desarrollo y en los ya desarrollados ha mostrado un uso intensivo de los recursos naturales. En un estudio sobre emisiones industriales en 14 países latinoamericanos, entre 1970-2000 Ortiz et al. (2005) reportan que los sectores más contaminantes fueron las refinerías de petróleo, hierro, acero y metales no ferrosos. Estos estudios indican que progresivamente los países latinoamericanos están aumentando las emisiones contaminantes al ambiente, a costa de un uso intensivo de los recursos naturales.

En Colombia, los desechos que se vierten principalmente al ambiente están constituidos por las aguas servidas, las 
emisiones atmosféricas, el uso indiscriminado de precursores químicos en actividades ilícitas, el uso de compuestos químicos en muy diversas actividades industriales y prácticas agrícolas inadecuadas (SánchezPérez 2002).

\section{CONTAMINACIÓN Y TOXICIDAD POR USO DEL CROMO}

Las principales fuentes de contaminación por cromo son aquellas relacionadas con la manufactura y uso de sus compuestos, por los beneficios que brinda en la elaboración de múltiples productos (Téllez et al. 2004). El cromo es utilizado para la fabricación de pigmentos y conservantes textiles, en la fabricación de cemento, en la industria del cuero, en aleaciones, pinturas, anti-incrustantes, catalizadores, agentes anticorrosivos, baterías, fungicidas, conservantes de madera, recubrimientos metálicos y electrogalvanizados. Los estados de interés industrial son el cromo hexavalente y el cromo trivalente (Téllez et al. 2004, Loayza 2006).

Este elemento puede estar presente en los cuerpos de agua como $\mathrm{Cr}^{+3}$, poco soluble y muy estable (elemento traza esencial), y como $\mathrm{Cr}^{+6}$, menos estable pero más soluble, con una alta movilidad entre sustratos, siendo mutagénico y carcinogénico en humanos, puede alterar seriamente el equilibrio biológico causando efectos tóxicos, ya que es rápidamente absorbido por las membranas biológicas (Téllez et al. 2004, Loayza 2006, Mancera-Rodríguez \& Álvarez 2006). La forma tóxica del cromo y sus compuestos son corrosivos y la exposición a ellos provoca reacciones alérgicas en la piel, en las vías respiratorias e irritación gastrointestinal, así como lesiones renales y hepáticas (Cuberos et al. 2009). La exposición a largo plazo a la presencia de cromo en el aire ha sido vinculada con el cáncer de pulmón. El grupo de mayor riesgo incluye a las personas de la industria de cromados y de pigmentos de cromo. Asimismo, existen riesgos similares entre los trabajadores de las minas de cromo, de industrias de aleación y galvanización de cromo, y soldadura de acero inoxidable (Loayza 2006, Cuberos et al. 2009).

En Colombia el 56\% de los usos del cromo corresponde a la metalurgia, el $20 \%$ a la industria refractaria y el $15 \%$ al sector manufacturero, que lo utiliza como producto químico (Téllez et al. 2004), por tanto la población expuesta ocupacionalmente debe estar sometida a un sistema de control tanto médico como de higiene industrial para prevenir consecuencias indeseables. Uno de los principales usos del cromo y fuentes de contaminación hídrica en Colombia es el curtido de pieles para la elaboración del cuero (Higuera et al. 2005, Cuberos et al. 2009, IDEAM 2010).
Este sector industrial está entre las seis tecnologías más negativas para el ambiente en Colombia, por el proceso de curtido al mineral, que vierte sus desechos a las fuentes de agua, además de que requiere una alta cantidad de insumos potencialmente tóxicos y produce alta eutrofización del agua, por el exceso de grasa, residuos de carne y piel que genera (DNSAV 2008).

\section{CURTIEMBRES E IMPACTO AMBIENTAL}

La curtición es el proceso por el cual las pieles de los animales como vacunos, ovinos y caprinos son convertidas en cuero (CNPML 2004). La curtición o curtido, es una técnica ancestral que permite estabilizar la materia orgánica, mediante una serie de etapas, en las que es necesario adicionar productos químicos que tienen consecuencias ambientales significativas, especialmente en los cuerpos de agua en los que son vertidos (Téllez et al. 2004). El producto final es el cuero o la piel curtida, que se convierte en un material duradero, casi imputrescible, apenas permeable al agua y a la vez suave, elástico y flexible (Téllez et al. 2004).

Las primeras actividades del sector curtiembres en Colombia datan de los años veinte en Antioquia y de los años cincuenta en Cundinamarca y posteriormente en Nariño, Quindío, Risaralda, Atlántico, Valle del Cauca, Tolima, Bolívar, Santander y Huila (CNPML 2004). El departamento de Cundinamarca posee el mayor número de curtiembres registradas (81,3\%) seguido de Nariño (9.6\%) y Valle del Cauca con 3,3\%. El sector de curtiembres en Colombia está compuesto principalmente por un 77\% microempresas, seguidas por pequeñas industrias (19\%), un $3 \%$ por medianas y un 1\% de gran industria (CNPML 2004). En el departamento del Valle del Cauca se encuentran alrededor de 20 curtiembres en El Cerrito y 4 en Cartago; las curtiembres elaboran principalmente productos como napas, nobuck, pullups, 90\% para el mercado nacional y $10 \%$ para el internacional (CINARA et al. 2006).

La comunidad empresarial está conformada por empresas familiares, de la cuales el $64 \%$ son micro empresas, $28 \%$ son pequeñas y $8 \%$ son medianas, el nivel de infraestructura de las curtiembres en general es bajo (CNPML 2004, CINARA et al. 2006). En Colombia, las curtiembres son industrias reconocidas por la utilización de compuestos de cromo y altamente contaminantes del recurso hídrico. Sus condiciones de operación contribuyen a la contaminación, debido a que la gran mayoría utilizan métodos y procedimientos rudimentarios en su operación (CNPML 2004, CINARA et al. 2006). 
La mayoría de las empresas cuenta con maquinaria obsoleta con niveles incipientes de tecnología, no realizan inversión en infraestructura adecuada y muchas de ellas tienen operarios con baja capacitación (CNPML 2004). La industria de curtidos es altamente contaminante y demandante de recursos naturales, según (CNPML. 2004), por cada $1000 \mathrm{Kg}$ de piel salada que entra al proceso se requieren $450 \mathrm{Kg}$ de insumos químicos; como producto se obtienen $200 \mathrm{Kg}$ de cuero acabado, $40 \mathrm{Kg}$ de solventes son emitidos a la atmosfera, $640 \mathrm{Kg}$ de residuos sólidos, $138 \mathrm{Kg}$ de agua que pierde la piel. El consumo de agua es de 15 - 40 $\mathrm{m}^{3} /$ tonelada de piel fresca.

Los parámetros anteriores, muestran que el proceso industrial de las curtiembres genera impactos negativos sobre el ambiente en general y en particular sobre el recurso hídrico que es reservorio de desechos orgánicos y químicos que afectan fuertemente la calidad del agua. Según IDEAM (2010), el sector de curtiembres aporta el 10\% de los SST, que se vierten a las aguas superficiales en Colombia; se han encontrado valores alarmantes de cromo en los sedimentos del río Bogotá (>37.3 mg/K) en las estaciones de Villapinzón y Tocancipá por la tradicional actividad de curtiembres en los municipios de Villapinzón y Chocontá. Razones más que suficientes para la búsqueda de soluciones que permitan disminuir y evitar el deterioro del medio ambiente y de la calidad de vida de los seres humanos, considerando que es necesario un equilibrio entre la productividad y la conservación del medio ambiente.

\section{PRODUCCIÓN MÁS LIMPIA}

La búsqueda de soluciones a la contaminación causada por el hombre se inició con la implementación de métodos y medidas de comando y control que pretendían frenar la contaminación. Pero desafortunadamente condujeron al abuso de la legislación, que llevó al razonamiento de que "si yo pago, tengo derecho a contaminar", la realidad mostró que, lo que se aplicaba era una simple dilución de la contaminación, o en muchos de los casos, tratamiento al final del proceso que requiere de inversiones onerosas y no siempre eficientes.

Sólo a partir de la década de los 90, empieza a darse un cambio hacia las estrategias preventivas, que aplican la filosofía del desarrollo sostenible, en el que producir eficientemente, implica ahorros y retornos económicos a las inversiones como resultado de un mejor uso de los recursos naturales, humanos y financieros (Pérez \& Rojas 2008). Por esta razón, tomar acciones encaminadas al logro de un desarrollo sostenible que conlleve al uso racional de los recursos naturales, la equidad social en el consumo y el ahorro debe ser una prioridad.

La evolución del enfoque en la temática de la contaminación del medio ambiente muestra un avance positivo en el manejo de los efluentes, desde la simple disposición de los residuos hasta la producción más limpia, que surge como una respuesta a la solución de la problemática ambiental de los sectores productivos en búsqueda de posibilidades reales de sostenibilidad y competitividad sectorial (Ministerio del Medio Ambiente 1997, CNPML 2004).

De acuerdo al Programa Ambiental de las Naciones Unidas (PNUMA) (PNUMA), la Producción Más Limpia (PML) se define como "la aplicación continua a los procesos, productos, y servicios, de una estrategia integrada $y$ preventiva, con el fin de incrementar la eficiencia en todos los campos, y reducir los riesgos sobre los seres humanos y el medio ambiente". El Ministerio del Medio Ambiente de Colombia adoptó su Política Nacional de Producción Más Limpia en 1997, para impulsar la nueva institucionalidad ambiental en el país (Ministerio del Medio Ambiente 1997). En el año 2002, el Ministerio de Ambiente, Vivienda y Desarrollo Territorial (MAVDT) expidió su Plan Estratégico Nacional de Mercados Verdes. Ambos actos políticos impulsaron un amplio rango de iniciativas que fueron desarrolladas por empresas, autoridades ambientales, comunidades y universidades (Política Nacional de Producción y Consumo Sostenible 2010).

Hoy en día, la Producción más Limpia y el Consumo Sostenible aún son estrategias emergentes de los sectores público y privado para afrontar los retos ambientales nacionales e internacionales (Política Nacional de Producción y Consumo Sostenible 2010). Los desarrollos relacionados con la globalización y la integración de la variable ambiental como un elemento central de la política pública y la competitividad, hacen evidente la importancia del enfoque preventivo, el aprovechamiento sostenible de los recursos, la consideración de variables de sostenibilidad en el diseño y desarrollo de proyectos de infraestructura, para asegurar un manejo responsable y sostenible, ante los crecientes y variados requerimientos de los mercados (Política Nacional de Producción y Consumo Sostenible 2010).

La estrategia de PML, es el punto de encuentro entre la productividad y el manejo ambiental, en la que se aplica el concepto de la prevención de la contaminación y eficiencia energética, mediante la implementación de las tres R's (Reciclaje, Reúso, Recuperación) tratamiento y disposición final de desechos (CINARA et al. 2006). Requiere del compromiso de los industriales, trabajadores y entidades gubernamentales, en búsqueda del equilibrio entre lo social, lo económico y lo ambiental, con un mejor manejo de los 
recursos y una mínima producción de desechos contaminantes.

En el caso particular de las curtiembres; la mayoría de estas industrias iniciaron la implementación del programa de PML en el año 2002, lo que les ha permitido mejorar algunos de los procesos productivos. Entre ellos la recuperación de cromo, que se viene realizando a través de métodos químicos de precipitación con $\mathrm{MgO}$ y redisolución con $\mathrm{H}_{2} \mathrm{SO}_{4}$ (Ministerio de Ambiente, Vivienda y Desarrollo Territorial. 2006), con eficiencias del $90 \%$. Este proceso de recuperación toma en promedio 4 días para tratar $8.5 \mathrm{~m} 3$ des aguas de curtido ${ }^{1}$, además de que consume energía, ya que requiere una temperatura de $45{ }^{\circ} \mathrm{C}$. Este es uno de los aspectos técnicos que se espera mejorar por medio de tecnologías biológicas con el desarrollo del presente proyecto. Los métodos biotecnológicos pueden ser utilizados tanto para el tratamiento de los desechos al final del proceso como para la recuperación y reúso de los efluentes del cromo en el proceso de curtido del cuero.

\section{BIORREMEDIACIÓN PARA LA REMOCION DE CROMO}

La biorremediación es un método de tratamiento biológico de contaminantes ambientales, en el que se requiere de organismos vivos como plantas y microorganismos, (principalmente bacterias y hongos) que destruyen $\mathrm{y} / \mathrm{o}$ transforman contaminantes peligrosos (Maier et al. 2009). Los procesos de biorremediación para el tratamiento de la contaminación por metales ofrecen una alta especificidad mediante mecanismos de bioadsorción, bioacumulación, biotransformación o biolixiviación (Fang et al. 2007, Kaushik et al. 2008, Okeke 2008) a formas no tóxicas del metal, además de ser más económicos y seguros que las tecnologías convencionales.

Los microorganismos han sido utilizados para el tratamiento de las aguas residuales desde 600 A.C, por los romanos y otras culturas (Maier et al. 2009), pero su desarrollo ha tomado mayor auge en los últimos veinte años. El potencial aplicativo de los microorganismos como agentes biolixiviadores (removedores de metales), puede usarse para promover la reducción de $\mathrm{Cr}^{+6}$ (Okeke 2008) y la biolixiviación de $\mathrm{Cr}^{+3}$ (Fang et al. 2007, Wang et al. 2007), tanto por la habilidad de los procesos enzimáticos directamente involucrados como por la producción de metabolitos altamente reductores, que contribuyen a

\footnotetext{
1 Comunicación personal. Departamento de Gestión ambiental. Curtipieles Ltda.
}

inmovilizar el metal. Se han reportado un buen número de estudios en los que microorganismos nativos de sitios contaminados con cromo muestran resistencia a este ión, debido a que poseen mecanismos activos o pasivos que les permiten removerlo o destoxificarlo. En ciertas especies se ha identificado la capacidad de remover el cromo por mecanismos de reducción tanto aerobia como anaerobia (Cheung \& Gu 2003, Lee et al. 2006, Wang et al. 2007, Okeke 2008, Yang et al. 2009, Zahoor \& Rehman 2009).

Por otro lado, Zahor \& Rehman (2009), encontraron que Bacillus sp. y Staphylococcus capitis pudieron reducir cromo hexavalente a trivalente con una eficiencia del $86 \%$ y $89 \%$ respectivamente, después de $144 \mathrm{~h}$ de exposición a efluentes industriales. Yang et al (2009), reportaron la capacidad de Intrasporangium sp., de reducir $\mathrm{Cr}^{+6}$, también en forma aerobia. En otro estudio con Bacillus sp. (Elangovan et al. 2006), se reportó la capacidad de tolerar el cromato y reducirlo mediante la actividad de una reductasa, combinada con un mecanismo de expulsión de cromo, estas características la hacen muy útil en biorremediación de ambientes contaminados con cromo.

Camargo et al (2004), evaluaron otra especie de Bacillus sp. ES 29 (ATCC: BAA-696) al inmovilizar las células y los extractos enzimáticos libres de células, en un birreactor; los resultados indicaron que tanto las células como el extracto enzimático presentaron capacidad reductora del $\mathrm{Cr}^{+6}$, con una eficiencia del 84 al 98\%, considerando al Bacillus sp., con un alto potencial para ser utilizado en modelos a escala real. Cheung \& Gu (2003), encontraron bacterias sulfatoreductoras (SRB), obtenidas a partir de sedimentos marinos contaminados con metales, capaces de reducir el $\mathrm{Cr}^{+6}$, en forma anaerobia. En otro estudio, en Dongducheon - Corea, aislaron bacterias autóctonas de suelos contaminados con metales pesados, con capacidad de reducir el $\mathrm{Cr}^{+6}$ en condiciones anaerobias, redujeron más del 99\% de $\mathrm{Cr}^{+6}$ en 96 $\mathrm{h}$ (Lee et al. 2006).

También se han reportado trabajos con efluentes de curtiembres, para la sedimentación de $\mathrm{Cr}^{+3}$ con bacterias acidófilas sulfo-oxidantes, en China (Fang et al. 2007), la lixiviación química con ácido sulfúrico se diseñó como el control. Los resultados mostraron que las bacterias sulfooxidantes y la adición de azufre elemental fueron eficaces en la eliminación del cromo. Después de 144 h el $98 \%$ del cromo fue biolixiviado, mientras que la lixiviación química eliminó sólo el $91 \%$ del total de cromo. En otro estudio en Haining China (Wang et al. 2007), la eficiencia de $A$. thiooxidans fue probada en lodos de curtiembres, para la solubilización del $\mathrm{Cr}^{+3}$ presente en un biorreactor de burbuja, a los 5 días alcanzó una remoción del 99.7\% . 
En el caso de los hongos se han realizado estudios sobre los mecanismos de interacción con el cromo, la mayoría de los cuales se han centrado en los procesos de biosorción y de bioacumulación. Las especies reportadas incluyen levaduras como Saccharomyces cerevisiae, Candida sp., Pichia sp., y los hongos filamentos Aspergillus sp., Penicillium sp., y Rhyzopus sp. En estudios recientes, se han descrito cepas fúngicas capaces de realizar el proceso de transformación de $\mathrm{Cr}^{+6}$ a especies reducidas. Con algunos de dichos organismos se han implementado procesos biotecnológicos de tratamiento de efluentes industriales (Gutiérrez et al. 2010).

A pesar que los estudios sobre organismos reductores de cromo han adquirido cierto auge en la última década en otros países (Kaushik et al. 2008, Gutiérrez et al. 2010), es necesario realizar estudios con bacterias nativas, ya que pocas investigaciones se han efectuado en países tropicales y muy pocas las realizadas en Colombia, donde las temperaturas medias $\left(24-28^{\circ} \mathrm{C}\right)$ y relativamente constantes permiten el desarrollo de una mayor diversidad de microorganismos, fenómeno que incrementa la probabilidad de encontrar especies con un alto potencial biorremediador hacia este metal.

\section{CONCLUSIONES}

El ser humano por su interés en el desarrollo y obtención de beneficios económicos ha logrado importantes avances en diferentes campos, pero ha afectado el ambiente por el manejo inadecuado de los recursos naturales, al haber sido considerados como donadores infinitos de materias primas y receptores de desechos y productos. Para la industria es fundamental adoptar estrategias ambientalmente sostenibles como la PML, este es el punto de encuentro entre la productividad y el manejo ambiental donde se aplica el equilibrio entre los componentes sociales, económicos y ambientales, al obtenerse una mayor eficiencia productiva con un mejor uso de los recursos y materiales así como una disminución de los desechos.

La biorremediación es una alternativa biológica muy eficiente para el tratamiento y/o recuperación de sustancias tóxicas y peligrosas como el cromo, por su alta especificidad y bajo costo, y es una tecnología que va de la mano con las estrategias de PML. Los mecanismos microbianos de biolixiviación y transformación química de cromo son promisorios para el desarrollo de procedimientos limpios y económicos, para la recuperación de cromo en el proceso del curtido del cuero y se complementan muy bien con la filosofía de la prevención y la conservación de los recursos naturales.

\section{REFERENCIAS}

CAMARGO, F. A. OKEKE, B. C. BENTO, F. \&, FRANKENBERGER, W. T. 2004. Hexavalent Chromium Reduction by Immobilized Cells and the Cell-Free Extract of Bacillus sp. ES 29. Bioremediation Journal. 8 (1-2) 23-30.

Centro Nacional de Producción Más Limpia - CNPML. 2004. Diagnóstico ambiental del sector curtiembre en Colombia. [Online]. Disponible: http://www.cnpml.org.

CHEUNG, K. H. \& GU J. D. 2003. Reduction of chromate $\left(\mathrm{CrO}_{4}^{-2}\right)$ by an enrichment consortium and an isolate of marine sulfate-reducing bacteria. Chemosphere 52: 15231529.

CINARA, CRPML, CDP del cuero. 2006. Cadena del cuero en el Valle del Cauca: PML para el mejoramiento de la competitividad, Feriva S.A. Universidad del Valle/Instituto Cinara-CRPML-CDP del Cuero Colombia, Cali. 171 pp.

CNPML "CENTRO NACIONAL DE PRODUCCIÓN MÁS LIMPIA". 2004. Proyecto Gestión Ambiental de la industria de curtiembres en Colombia. Manual Ambiental Sectorial. [Online]. Disponible: http://www.cnpml.org.

MINISTERIO DE AMBIENTE, VIVIENDA Y DESARROLLO TERRITORIAL COLOMBIA. 2010. Política Nacional de Producción y Consumo Sostenible, Bogotá D.C. 71 pp.

CUBEROS, E. A. RODRÍGUEZ \& PRIETO E. 2009. Niveles de cromo y alteraciones de salud en una población expuesta a las actividades de curtiembres en Bogotá, Colombia. Revista de Salud Pública 11(2): 278-289.

DNSAV. 2008. Dirección nacional de Servicios Académicos Virtuales. Problemas Críticos Colombianos. [Online]. Disponible: http://www.virtual.unal.edu.co

ELANGOVAN, R. ABHIPSA, S. ROHIT, B. LIGY, B. \& CHANDRARAJ, K. 2006. "Reduction of $\mathrm{Cr}(\mathrm{VI})$ by a Bacillus sp.” Biotechnology Letters 28: 247-252.

FANG, D. JIN, C. \& ZHOU, L. X. 2007. Removal of Cr from tannery sludge by indigenous sulfur-oxidizing bacteria. Journal of Environmental Science and Health A(42): 20652069.

GLIGO, N. 2001. La dimensión ambiental en el desarrollo de América Latina, CEPAL, Comisión Económica para América 
Ambiente y Sostenibilidad 2011 (1): 25-31

Revista del Doctorado Interinstitucional en Ciencias Ambientales

ISSN: 2339-3122

Latina y el Caribe, Santiago de Chile: Naciones Unidas 2332.

GONZÁlEZ DE MOLINA, D. 1993. Historia y medio ambiente. Ediciones de la Universidad Complutense S.A. Madrid. EUDEMA, S: 45-62.

GUTIÉRREZ, J. F. ESPINO, A. CORDEÑO, A. ACEVEDO, F. REYNA, G. FERNÁNDEZ, F. TOMASINI, A. WROBEL, K. \& WROBEL, K.. 2010. Mecanismos de interacción con cromo y aplicaciones biotecnológicas en hongos. Revista latinoamericana de Biotecnología Ambiente Algal, 1: 47-6 3.

HENRY, J. G. \& HEINKE, G. W. 2006. Ingeniería Ambiental Prentice Hall. Mexico: 3-48.

HIGUERA, O. F. ESCALANTE, H. \& LAVERDE D. 2005. Reducción del cromo contenido en efluentes líquidos de la industria del cuero, mediante un proceso adsorción desorción con algas marinas. Scientia et Technica 11(29): 115-120.

IDEAM. 2010. Estudio Nacional del Agua. Instituto de Hidrología Meteorología y Estudios Ambientales. Bogotá. D.C.

KAUSHIK, A. JUWARKAR, A. MALIK \& S. SATYA. 2008. Biological removal of $\mathrm{Cr}$ (VI) by bacterial isolates obtained from metal contaminated sites, Journal of Environmental Science and Health A(43): 419-423.

LEE, S. E. LEE, J. U. LEE, J. S \& CHON, H.T. 2006. Effects of indigenous bacteria on $\mathrm{Cr}(\mathrm{VI})$ reduction in $\mathrm{Cr}$-contaminated sediment with industrial wastes. Journal of Geochemical Exploration 88: 41-44.

LOAYZA, J. E. 2006. Estudio de Investigación: Gestión Integral de Residuos Peligrosos. Boletín electrónico informativo sobre productos y residuos químicos. [Online] 2(13): 1-4. Disponible: http://www.sertox.com.ar.

MAIER, R. M. PEPPER, I. L. \& GERBA, C. P.. 2009. Environmental Microbiology, 2nd ed., Academic Press. Elsevier, San Diego California. 585 pp.

MANCERA-RODRÍGUEZ, N. J. ÁLVAREZ, R. 2006. Estado del conocimiento de las concentraciones de mercurio y otros metales pesados en peces dulceacuícolas de Colombia. Acta Biológica Colombiana 11(1): 3-23.

MINISTERIO DE AMBIENTE, VIVIENDA Y DESARROLLO TERRITORIAL. 2006. Guía Ambiental para la industria del curtido y preparado de cueros. 2nd ed. Panamericana
Formas e impresos S.A, Bogotá D.C:138.

MINISTERIO DEL MEDIO AMBIENTE. República de Colombia. 1997. Política Nacional de Producción más limpia. [Online]. Disponible: http://www.cnpml.org

OKEKE, B. C. 2008. Biorremoval of hexavalent chromium from water by a salt tolerant bacterium. Exiguobacterium sp. GS1. J. Ind. Microbiol Biotechno, vol 35: 1571-1579.

ORTIZ, L. SCHUSCHNY, A.R. \& GALLOPÍN, G.C. 2005. Evolución de las emisiones industriales potenciales en América Latina, 1970-2000 CEPAL Serie Medio Ambiente y desarrollo. No. 97, Santiago de Chile: Naciones Unidas.

PÉREZ, M. A. \& ROJAS, J. 2008. Documentos de política pública: los aportes de la Academia hacia el desarrollo sostenible en Colombia. Tomo 1, vol. 3: 91 pp.

PROGRAMA AMBIENTAL DE LAS NACIONES UNIDAS (PNUMA). [Online]. Disponible: http://www.unep. org/ SÁNCHEZ-PÉREZ, G. 2002. Desarrollo y medio ambiente: una mirada a Colombia. Revista Economía y Desarrollo. Univ. Autónoma de Colombia, Bogotá. 79-98 pp.

SARLINGO, M. 1998. “Venenos en la sangre. Breve descripción de la contribución de la especie humana a la contaminación del planeta. Proyecto ecología política, interdisciplinariedad y cambio social". Publicación electrónica de la facultad de Ciencias Sociales. UNICEN. [Online] Disponible: http:/ / www.soc.unicen.edu.ar.

TÉLlEZ, J. CARVAJAL, R. M. \& GAITÁN, A. M. 2004. Aspectos toxicológicos relacionados con la utilización del cromo en el proceso productivo de curtiembres. Revista de la Facultad de Medicina de la Universidad Nacional de Colombia. 52(1): 50-61.

WANG, Y-S. PAN, Z-Y. Xu, J-M. LANG \& ZHENG, Y-G. 2007. Bioleaching of chromium from tannery sludge by indigenous Acidithiobacillus thiooxidans. Journal of Hazardous Materials, 147: 319-324.

YANG, J. He, M. \& WANG, G. 2009. Removal of toxic chromate using free and immobilized $\mathrm{Cr}(\mathrm{VI})$-reducing bacterial cells of Intrasporangium sp. Q5-1". World Journal of Microbiol Biotechnology, 25: 1579-1587.

ZAHOOR, A. \& REHMAN, A. 2009. Isolation of Cr (VI) reducing bacteria from industrial effluents and their potential use in bioremediation of chromium containing wastewater. Journal of Environ. Science 21: 814-820. 